\title{
SENSIBILIZAÇÃO AMBIENTAL: EXPERIÊNCIA EM UMA COOPERATIVA DE CRÉDITO NO NOROESTE GAÚCHO
}

Ana Paula Satler ${ }^{1}$, Danni Maisa da Silva², Divanilde Guerra ${ }^{2}$, Ramiro Pereira Bisognin², Robson Evaldo Gehlen Bohrer ${ }^{2}$, Marciel Redin ${ }^{2}$, Vanderlei Franck Thies ${ }^{3}$, Eduardo Canepelle ${ }^{4}$

\begin{abstract}
RESUMO - A educação, especialmente no âmbito ambiental, deve despertar a compreensão, necessidade de comprometimento com o meio para que a sociedade assuma responsabilidades, para enfrentar os desafios ambientais da atualidade. O trabalho teve como objetivo desenvolver ações de Educação Ambiental com associados e colaboradores de uma Cooperativa de Crédito da Região Noroeste do Rio Grande do Sul, a fim de promover a sensibilização ambiental, mudanças no comportamento e atitudes relacionadas ao meio ambiente, bem como realizar uma análise sobre a importância dos aspectos ambientais (reduzir, repensar, reaproveitar, reciclar e recusar consumir produtos que gerem impactos socioambientais) relacionados ao cotidiano dos participantes. O método utilizado foi a realização inicial de uma revisão bibliográfica, aplicação de questionários, adaptados de Prieto (2012), para 272 pessoas, com a realização posterior de ações de Educação Ambiental, norteadas pela Agenda Brasileira 21. Determinou-se que a grande maioria dos participantes possui pouco interesse em assuntos ligados às causas ambientais, e desenvolvem poucas ações ligadas ao meio ambiente. Nas ações de Educação Ambiental foram envolvidas 327 pessoas, onde se buscou mostrar de maneira prática aos participantes de atitudes que podem ser realizadas no cotidiano para a melhoria e preservação do meio ambiente. Portanto, com a execução do trabalho foi possível proporcionar momentos de compreensão, responsabilidades individuais e em conjunto, além da reflexão com um público da Cooperativa de Crédito, buscando assim, a construção de um mundo mais sustentável e cooperativo.
\end{abstract}

Palavras chave: cooperativismo; educação ambiental, sustentabilidade.

\section{ENVIRONMENTAL AWARENESS: EXPERIENCE IN A CREDIT COOPERATIVE IN THE NORTHWEST OF THE STATE OF RIO GRANDE DO SUL}

\begin{abstract}
Education, especially in the environmental field, must arouse understanding, the need for commitment to the environment for society to take responsibility, to face today's environmental challenges. This work aimed to develop Environmental Education actions with associates and collaborators of a Credit Cooperative of the Northwest Region of Rio Grande do Sul, in order to promote environmental awareness, changes in behavior and attitudes related to the environment, as well as to carry out an analysis of the importance of environmental aspects (reduce, rethink, reuse, recycle and refuse to consume products that generate social and environmental impacts) related to the daily lives of participants. The method used was the initial realization of a bibliographic review, application of questionnaires, adapted from Prieto (2012), to 272 people, with the subsequent accomplishment of Environmental Education actions, guided by the Brazilian Agenda 21. It was determined that the great majority participants have little interest in issues related to
\end{abstract}

\footnotetext{
${ }^{1}$ Administradora. Especialista em Gestão e Sustentabilidade Ambiental pela Universidade Estadual do Rio Grande do Sul - UERGS, Unidade em Três Passos.

2 Professor (a) da UERGS, Unidade em Três Passos. Endereço para correspondência: Rua Cipriano Barata, $\mathrm{n}^{\circ} 211$. Bairro Érico Veríssimo - Três Passos. CEP: 98600-000. Contato: (55) 3522-2895. E-mail: danni-silva@uergs.edu.br.

${ }^{3}$ Engenheiro Agrônomo, Mestre e Doutorando no Programa de Pós-Graduação em Desenvolvimento Rural (PGDR), na Universidade Federal do Rio Grande do Sul (UFRGS), Porto Alegre.

${ }^{4}$ Graduando do Curso de Bacharelado em Agronomia da UERGS, Unidade em Três Passos.
} 
environmental causes, and develop few actions related to the environment. In the Environmental Education actions, 327 people were involved, aiming to show the participants in a practical way the attitudes that can be done in daily life for the improvement and preservation of the environment. Therefore, with the execution of the work it was possible to provide moments of understanding, individual and joint responsibilities, as well as reflection with an audience of the Credit Cooperative, thus seeking to build a more sustainable and cooperative world.

Keywords: cooperativism, environmental education, sustainability.

\section{INTRODUÇÃO}

Os seres humanos habitam hoje um meio modificado onde indústrias, ciências e tecnologias, transformaram a natureza com ações em que podem estar colocando em risco a sobrevivência humana. Com isso, torna-se necessário buscar soluções para atuais problemas ambientais, e de acordo com Zimmermann (2016), a educação ambiental é grande aliada para o enfrentamento destes problemas.

A Organização das Nações Unidas para Educação, Ciência e Cultura (UNESCO) definiu, em 1990, que a educação ambiental é um processo em que os indivíduos devem tomar consciência do seu meio ambiente, adquirindo conhecimentos, habilidades, experiências, valores e a determinação que os tornam capazes de agir, individual ou coletivamente, na procura de soluções para os problemas ambientais, presentes e futuros (UNESCO, 1990).

De acordo com Art. $1^{\circ}$ da Lei $n^{\circ} 9.795 / 1999$, a Educação Ambiental é definida como conjunto de processo por meio dos quais os indivíduos e a coletividade constroem valores sociais, conhecimentos, habilidades, atitudes e competências voltadas para a conservação do meio ambiente, bem de uso comum do povo, essencial à sadia qualidade de vida (BRASIL, 1999). Sendo assim, a Educação Ambiental se constitui como uma forma abrangente de educação, por meio da qual pretende-se envolver todos os cidadãos, de forma participativa e permanente, como uma forma de incentivo e inspiração à consciência sobre a problemática ambiental.

Cooperativismo, por sua vez, corresponde a uma doutrina, a qual visa à renovação social através da cooperação dos seus participantes (Pinho, 1966), regida pela Lei Geral do Cooperativismo, $n^{\circ} 5.764$, de 16 dezembro de 1971, que informa, em seu artigo $4^{\circ}$, que as cooperativas são sociedades de pessoas conforme natureza jurídicas próprias, de natureza civil, não sujeitas à falência, constituída a gerar serviços para os associados (....). O Cooperativismo é um movimento, uma filosofia de vida e um modelo socioeconômico capaz de unir desenvolvimento econômico e bem-estar social (OCB SESCOOP, 2014) e atualmente é uma importante força para a economia brasileira. Segundo a Organização das Cooperativas Brasileiras-OCB (2014), o cooperativismo é a união voluntária de pessoas que buscam soluções econômicas e sociais com base em interesses comuns, proporciona a capacidade de somar e dividir entre todos, tendo as pessoas como peça principal do processo. Como o cooperativismo é um modelo socioeconômico que busca unir desenvolvimento econômico e bem-estar social, pode ser considerado como aliado na busca pelo desenvolvimento sustentável, desenvolvimento este que satisfaz as necessidades do presente sem comprometer a capacidade das gerações futuras (WCED, 1991).

As ações de educação ambiental podem ter seus resultados potencializados quando são realizadas em instituições cooperativas, pois as cooperativas, na consecução de seus objetivos, direta ou indiretamente, trabalham para promover o desenvolvimento sustentável da comunidade local ou regional nas quais estão inseridas. Namorado (1993) relata que o desenvolvimento de atividades relacionadas à educação ambiental em empresas possui um papel muito importante, porque desperta em cada funcionário, e no caso de cooperativas, aos associados e à sociedade, o interesse para a ação e para a busca de soluções concretas para os problemas ambientais que ocorrem no seu dia-adia, no trabalho, na execução de sua tarefa, onde ele tem poder de atuação para a melhoria da qualidade ambiental do funcionário e dos seus colegas.

Verifica-se que são raras as ações que abordem a questão da educação ambiental no âmbito empresarial ou em cooperativas, sendo importante desenvolver ações que trabalhem a educação ambiental, tais como, estabelecimento de metas ambientais, implementação da ferramenta 5Rs (reduzir, repensar, reaproveitar, reciclar e recusar consumir produtos de significativos impactos socioambientais), sensibilização de colaboradores e comunidade em geral, desenvolvimento de projetos e atividades, auditorias ambientais, análise de ciclo de vida (ACV), entre outras ações que promovam o desenvolvimento sustentável das regiões onde estão inseridas. 
Neste contexto, objetivou-se desenvolver ações de Educação Ambiental com associados e colaboradores de uma Cooperativa de Crédito da Região Noroeste do Rio Grande do Sul, a fim de promover a sensibilização ambiental e mudanças no comportamento e atitudes relacionadas ao meio ambiente. Desta forma, o estudo realiza uma análise sobre a importância dos aspectos ambientais, como 5Rs, relacionados ao cotidiano dos participantes.

\section{MATERIAL E MÉTODOS}

O estudo foi realizado em uma unidade de uma Cooperativa de Crédito localizada na Região Noroeste do RS, no período de novembro de 2016 a junho de 2017. A pesquisa se caracteriza como quantitativa e qualitativa e teve como finalidade principal gerar conhecimentos para a solução dos problemas encontrados na realidade estudada, referente à Educação Ambiental. O estudo foi realizado com a participação de 282 pessoas, das quais 29 eram colaboradores da Cooperativa de Crédito e 253 eram associados. A pesquisa foi constituída em três etapas, como segue.

A primeira etapa se baseou em uma pesquisa bibliográfica, que também serviu de embasamento para elaboração dos questionários. $\mathrm{Na}$ segunda etapa foi realizada a coleta dos dados que por meio da aplicação de questionários aos colaboradores e associados da Cooperativa de Crédito, sendo que os questionários aplicados estavam relacionados e embasados na Agenda 21 (MMA, 2009) que priorizou como seus princípios a política dos 5Rs (reduzir, repensar, reaproveitar, reciclar e recusar consumir produtos que gerem impactos socioambientais significativos). Durante a elaboração dos questionários foi levado em consideração o público alvo da cooperativa, composto por agricultores, com isso buscou-se trabalhar na organização de questões que levassem a respostas diretas e de fácil compreensão, adaptando assim a metodologia de Prieto (2012). A aplicação destes questionários teve como finalidade verificar os conhecimentos que os colaboradores e associados da Cooperativa de Crédito possuíam sobre o meio ambiente. Para tal, inicialmente foram aplicadas questões relacionadas à caracterização do público participante relacionadas ao gênero, grau de instrução, renda média, entre outras. Na sequência, os participantes foram questionados quanto ao seu interesse em relação às questões ambientais; sobre a separação dos resíduos e formas de descarte de objetos; se desenvolve ações sustentáveis relacionadas aos recursos naturais; sobre possíveis soluções para os problemas ambientais e, aos agricultores foram ainda aplicadas algumas questões relacionadas ao uso de agrotóxicos em suas lavouras.
Após a aplicação dos questionários teve início a terceira etapa, na qual foram desenvolvidas atividades práticas relacionadas à educação ambiental, a fim de contribuir no conhecimento, valores, atitudes dos associados e colaboradores da cooperativa. Por meio das atividades práticas buscou-se contribuir na criação de novo paradigma onde os colaboradores e associados da Cooperativa de Crédito, compreendam a importância que o meio ambiente como todo tem para seres humanos, e assim preserve o mesmo de maneira eficiente, ou seja, não apenas com discursos de sustentabilidade, mas sim com atitudes concretas, as quais foram demonstradas com atividades práticas.

Após a realização das três etapas da pesquisa, os dados foram tabulados e as respostas dos questionários foram, em sua grande maioria organizadas em figuras e tabelas, para posterior análise e discussão. Para isso, o item Resultados e Discussão é apresentado em diferentes subtópicos, com vistas a facilitar a compreensão das respostas obtidas no questionário aplicado, iniciandose com a caracterização do público participante deste trabalho. Na sequência, são apresentados dados e informações relacionados às questões ambientais, sendo o item Resultados e Discussão finalizado com a apresentação das atividades práticas e teóricas relacionadas à Educação Ambiental.

\section{RESULTADOS E DISCUSSÃO}

\section{Perfil dos participantes da pesquisa}

A Cooperativa de Crédito estudada foi fundada em 2004 com a missão de promover a inclusão social da agricultura familiar por meio do acesso ao crédito, da poupança e da apropriação do conhecimento, visando o desenvolvimento local e a sustentabilidade institucional (CRESOL, 2017). Portanto, possui a visão de crescer junto com o seu quadro social para que possa atender um maior número de famílias agricultoras, oferecendo crédito e acesso a serviços financeiros, buscando assim promover o desenvolvimento rural dos locais onde está inserida.

De acordo com Cresol (2017), os valores institucionais da cooperativa se caracterizam como excelência, ética, honestidade, transparência e responsabilidade social; seus princípios são caracterizados como interação solidária, formação, capacitação e organização dos associados, descentralização das decisões, crescimento horizontal, democratização e profissionalização do crédito, desenvolvimento social e sustentabilidade, um dos princípios da cooperativa. 
A Unidade Cooperativa de Crédito, onde realizouse o estudo, possui como público total 3.022 pessoas ativas, entre associados e colaboradores. Destas, 272 pessoas participaram da presente pesquisa, sendo 77 do gênero feminino, representando assim, $28 \%$ dos participantes e 195 do gênero masculino, o que representou $72 \%$ dos participantes. A questão do gênero é um aspecto importante que deve ser considerado na análise dos diferentes contextos e, consequentemente, na análise da importância dos aspectos ambientais.

No que diz respeito à profissão e ao grau de instrução dos participantes da pesquisa $54,8 \%$ são agricultores, destes, 5,37\% possuem ensino fundamental incompleto, $6,71 \%$ possuem ensino fundamental completo, $16,78 \%$ ensino médio incompleto, $48,32 \%$ ensino médio completo, $10,74 \%$ possuem ensino superior completo, $10,07 \%$ possuem ensino superior incompleto e $2,01 \%$ pósgraduação.

No meio rural de países em desenvolvimento, como é o caso do Brasil, houve uma modernização da agricultura que possibilitou diferenças estruturais históricas principalmente de produção, o que revela que a terra foi subordinada ao uso capital.(Gliessman, 2001). O mesmo autor enfatiza que a difusão da modernização da agricultura ocorre concomitante com a especialização dos agricultores, ou seja, quanto maior a qualificação, mais moderno será seu processo produtivo.

De acordo com Gliessman (2001) a tecnologia e a modernização trazem consequências para agricultura, pois visam maximizar eficiência produtiva das áreas de terras implementando técnicas como o monocultivo, que tende a favorecer o cultivo intensivo do solo, a aplicação de fertilizantes inorgânicos, a irrigação, o controle químico de pragas e as variedades especializadas de plantas, trazendo grandes problemas ambientais. Analisando essas afirmações pode-se compreender o porquê $22,82 \%$ dos agricultores entrevistados estão buscando se especializar, cursando ensino superior, ou já o tendo cursado.

Ainda relacionado às tecnologias e modernização das propriedades rurais, Medeiros e Ribeiro (2018) afirmam que as condições econômicas, sociais e políticas brasileiras indicam disparidade entre diferentes classes sociais que marginaliza diretamente as classes menos favorecidas, como os agricultores com baixo poder aquisitivo, pequenos proprietários e agricultores familiares com área restrita. A modernização da agricultura brasileira tendeu a favorecer o aumento da participação relativa das camadas mais ricas na apropriação da renda total (Medeiros \& Ribeiro, 2018).
Conforme se observa na Tabela 1, grande parte dos agricultores envolvidos na pesquisa $(63,76 \%)$ ainda possuem renda entre 1 e 7 salários mínimos mensais, possuindo assim, menos recursos financeiros para implementar técnicas modernas de altos investimentos tecnológicos para produção agrícola em grande escala.

Tabela 1 - Renda média mensal do público participante da pesquisa, em 2017

\begin{tabular}{lcc}
\hline Renda/Mês & $\begin{array}{c}\text { Total de } \\
\text { participantes }(\%)\end{array}$ & $\begin{array}{c}\text { Agricultores } \\
(\%)\end{array}$ \\
\hline Até 1 salário mínimo & 20,96 & 31,54 \\
\hline $\begin{array}{l}\text { Entre 1 e } 3 \text { salários } \\
\text { mínimos }\end{array}$ & 48,53 & 46,98 \\
$\begin{array}{l}\text { Entre 4 e 7 salários } \\
\text { mínimos }\end{array}$ & 16,54 & 16,78 \\
\hline $\begin{array}{l}\text { Entre 7 a 10 salários } \\
\text { mínimos }\end{array}$ & 8,46 & 2,68 \\
$\begin{array}{l}\text { Mais de 10 salários } \\
\text { mínimos }\end{array}$ & 5,51 & 2,01 \\
\hline
\end{tabular}

Ao se analisar paralelamente o grupo dos agricultores de menor renda, considerando-se entre estes os agricultores familiares, que são o maior público do estudo, e consequentemente o maior público participante da pesquisa, autores como Almeida et al. (2001) destacam que agricultores familiares com renda de até R\$30.000,00 ao ano apresentam melhores condições de incorporar estratégias de sustentabilidade em suas propriedades. Sendo assim, a proposta de desenvolver atividades relacionadas a educação ambiental na cooperativa apresenta enorme potencial para criação de uma nova visão pelos agricultores capaz de despertar uma maior atenção para a preservação do meio ambiente e estimular o uso de práticas agrícolas mais sustentáveis.

\section{A importância dos aspectos ambientais}

Das 272 pessoas que participaram do estudo $11,40 \%$ informaram possuírem interesse nas questões relacionadas ao meio ambiente (Figura 1). No entanto, $88,60 \%$ afirmaram que possuem pouco interesse em relação às questões ambientais ou nenhum interesse pelo tema. Os participantes com renda mensal superior demonstraram estar mais interessados pelas questões relacionadas com o meio ambiente, quando comparados aos participantes com renda mensal inferior. Em análise comparativa, a renda 
com o interesse ao meio ambiente pode-se observar: as pessoas com renda de até 1 salário mínimo, em sua maioria são pouco interessadas pelo meio ambiente $(87,72 \%$ dos entrevistados), enquanto que $8,77 \%$ afirmaram ser muito interessados e $1,75 \%$ disseram não ter interesse ou não souberam avaliar; já entre as pessoas com renda entre 1 e 3 salários mínimos $86,36 \%$ responderam estar pouco interessados, $12,12 \%$ disseram-se muito interessados e $1,52 \%$ afirmaram não ter interesse. Dos participantes com renda mensal entre 4 e 7 salários mínimos, 84,44\% afirmaram estar pouco interessados; $13,33 \%$ muito interessados e $2,22 \%$ que não possuem nenhum interesse; os entrevistados que possuem renda entre 7 e 10 salários mínimos, 78,26\% afirmaram estar pouco interessados; $8,70 \%$ muito interessados e $13,04 \%$ afirmaram não possuírem nenhum interesse; das pessoas estudadas que possuem renda mensal superior a 10 salários mínimos $60 \%$ afirmaram estar pouco interessados, $13,33 \%$ muito interessados e $26,67 \%$ informaram não possuir nenhum interesse sobre as questões ambientais.

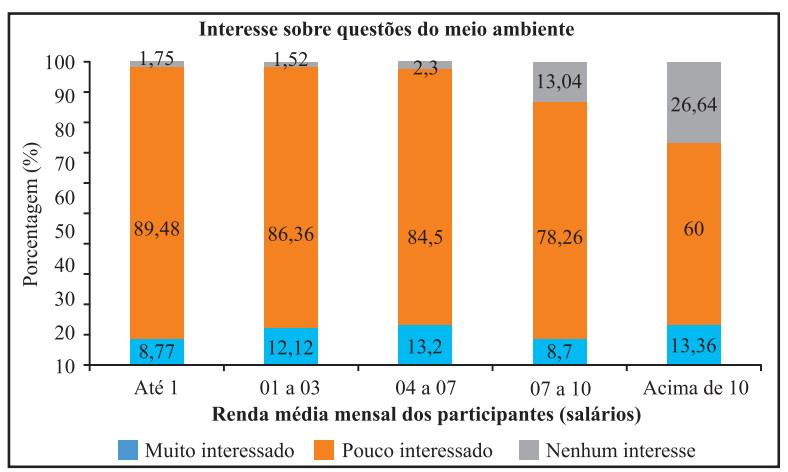

Figura 1 - Interesse dos participantes sobre as questões relacionadas ao meio ambiente, de acordo com a renda média mensal.

Assim, de maneira geral, todas as faixas de renda informaram que possuem pouco interesse relacionado ao meio ambiente, tornando a temática bastante importante e pertinente, pois o interesse pelo tema pode ser considerado como um dos primeiros passos para a mudança de atitudes em prol da sustentabilidade.

Como observado $88,60 \%$ dos participantes demonstram pouco interesse sobre as questões relacionadas ao meio ambiente, sendo muito importante a realização de trabalhos de Educação Ambiental. Segundo Leroy et al. (2002), para a compreensão das questões relacionadas ao meio ambiente é preciso que este tema seja trabalhado ou estudado de alguma forma com a população, pois, de maneira geral, as pessoas não conseguem descrever ou dialogar sobre determinado assunto e também não conseguem desenvolver ações com foco na sustentabilidade se o tema não é trabalhado ou estudado. Para a criação de um novo paradigma onde pessoas demonstrem maior interesse por questões relacionadas ao meio ambiente, segundo Muggler et al. (2006), é necessário desenvolver atividades relacionadas ao processo educativo, pois a educação contribui de forma efetiva neste processo, uma vez que oferece instrumentos para elaborar e reelaborar valores, atitudes e condutas.

Quando os participantes foram questionados sobre a separação dos resíduos, ou seja, se os mesmos separavam o resíduo sólido seco do resíduo sólido orgânico, 95,59\% afirmaram que separam os mesmos antes de encaminhá-lo para a coleta municipal. O grupo que não realiza a separação dos resíduos é basicamente caracterizado por pessoas que possuem renda média mensal de 1 salário mínimo, que possuem ensino fundamental completo ou incompleto, residentes no meio urbano. No que tange à separação dos resíduos sólidos, a base legal sobre o assunto é definida pela Lei $n^{\circ} 12.305 / 2010$ que institui a Política Nacional de Resíduos Sólidos-PNRS (BRASIL, 2010), que reúne um o conjunto de princípios, objetivos, instrumentos, diretrizes, metas e ações adotados pelo estado ou particulares, com vistas à gestão integrada e ao gerenciamento ambientalmente adequado dos resíduos sólidos.

Dos entrevistados 72,43\%, afirmaram que descartam os objetos que estão sem uso, $21,32 \%$ fazem doações e apenas 6,25\% realizam reutilização. Neste sentido, Kuhnen (1995) afirma que a reciclagem dos resíduos se apresenta como uma alternativa fundamental para conter o problema da produção de resíduos, uma vez que ela reduz o volume final dos mesmos, que precisariam ser incinerados ou aterrados. Ainda esta solução gera renda às pessoas que participam do processo de reciclagem, que geralmente é constituído por indivíduos e famílias marginalizadas pela sociedade. Na mesma perspectiva, O'Leary \& Walsh (1999) afirmam que a reciclagem dos resíduos sólidos é uma solução viável que proporciona a preservação dos recursos naturais, economia de energia, redução de área que demanda o aterro sanitário, geração de emprego e renda, assim como a conscientização da população para questões ambientais. Ou seja, medidas capazes de incentivar a realização da reciclagem e do reuso dos resíduos sólidos devem ser pensadas e trabalhadas, com vistas na melhoria das condições ambientais no curto, médio e longo prazo, pois esta prática além contribuir de maneira eficiente com meio ambiente ainda se apresenta como fonte de renda para algumas famílias. 
O tipo de lâmpada utilizada influencia no consumo de energia elétrica de modo que existem alguns tipos de lâmpadas elétricas que são aliadas do meio ambiente e do consumidor, pois consomem menos energia. Neste sentido, os participantes foram questionados sobre o tipo de lâmpadas que preferem comprar e 46,32\% responderam que preferem compram lâmpadas fluorescentes, pelo menor custo financeiro; $19,12 \%$ informaram que compram lâmpadas comuns; $13,97 \%$ que compram ambos os tipos sem distinção, pois apresentam valores financeiros similares; e 20,59\% informaram que compram lâmpadas do tipo LED (Light Emitter Diode) com vistas na economia, durabilidade e custo versus benefício ao meio ambiente.

Segundo Francisco (2009) grande parte da energia elétrica do Brasil é proveniente de usinas hidrelétricas as quais dependem de um recurso natural para gerar energia, o que torna a redução do consumo energético algo muito importante para a preservação dos recursos naturais. Porém existem diversos artifícios para reduzir o consumo de energia, sendo um deles a substituição de lâmpadas ineficientes como as incandescentes por lâmpadas eficientes, como as LEDs (Saidur, 2009). Santos et al. (2015) afirmam que a lâmpada de LED é um progresso da tecnologia que vem ganhando destaque, pois estas são dispositivos semicondutores preenchidos com gases e revestidos com diferentes materiais de fósforo.
A utilização do LED em forma de lâmpada, é muito interessante no âmbito ambiental, pois seu consumo de energia é inferior às lâmpadas convencionais, como as incandescentes e as fluorescentes compactas. Santos et al. (2015) destacam as características e possibilidades de descarte final de resíduos das lâmpadas de LED, além da sua durabilidade já que o LED é produzido com materiais atóxicos ao meio ambiente, podendo ser descartado sem a necessidade de uma destinação e disposição final especiais. A sua durabilidade é outro aspecto interessante, pois demanda menos trocas o que, consequentemente, gera menos descartes no ambiente (Santos et al., 2015).

Ações desenvolvidas para a melhoria e preservação do meio ambiente

A qualidade da vida dos cidadãos está diretamente relacionada com o meio ambiente que os cerca. Segundo Bohner et al. (2011), na sociedade moderna, o meio ambiente é um sistema, um conjunto de diversas partes interligadas e organicamente articuladas, que influenciam na qualidade de vida das pessoas. Sendo assim, buscou-se avaliar as ações cotidianas em prol do meio ambiente que são realizadas pelos envolvidos na pesquisa, cujos os dados são apresentados na Figura 2.

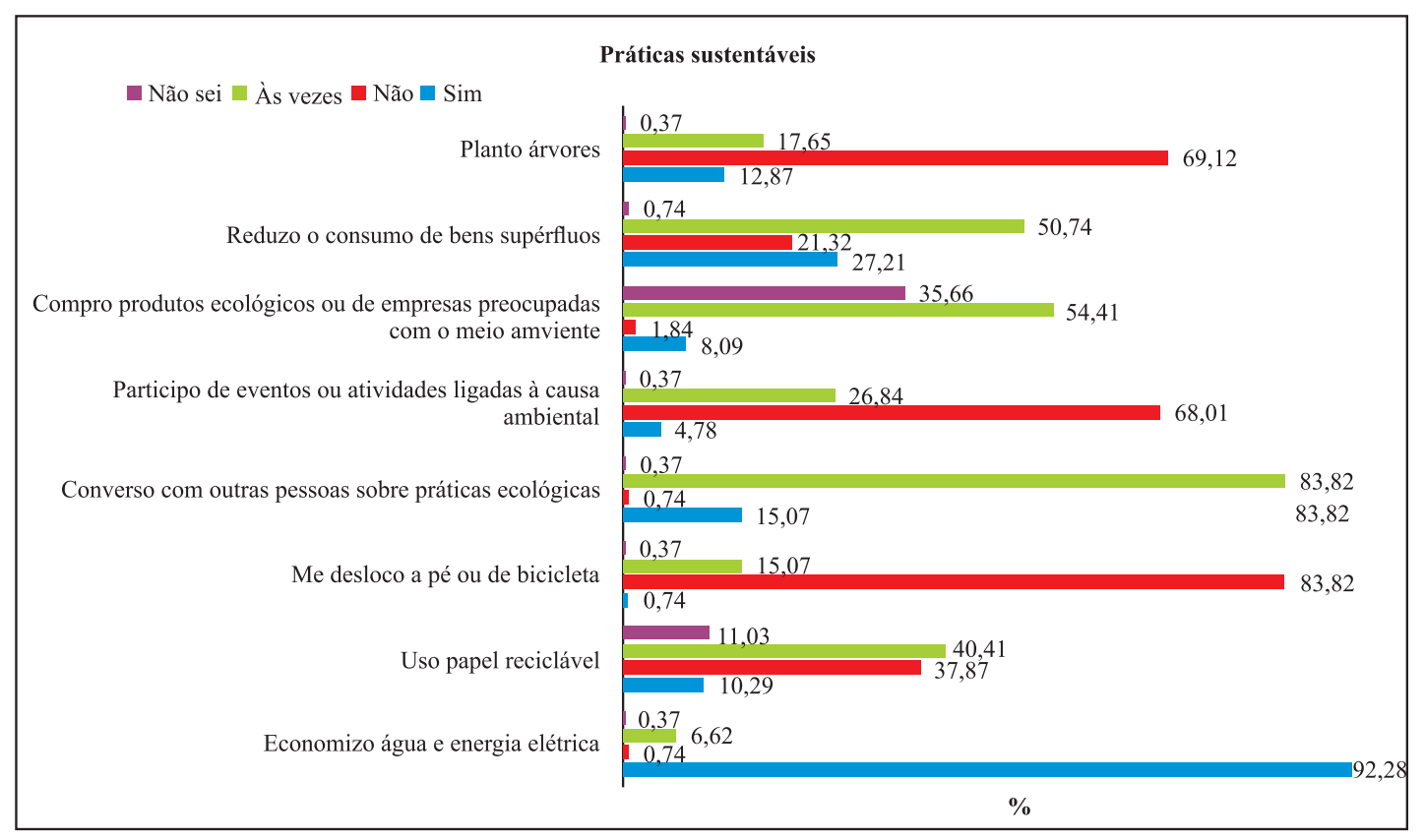

Figura 2 - Ações realizadas pelo público participante da pesquisa em relação ao meio ambiente, cujos dados são apresentados em percentagem $(\%)$. 
Destaca-se que a grande maioria dos envolvidos na pesquisa, desenvolve ações sustentáveis relacionadas aos recursos naturais, pois $92,28 \%$ afirmaram que economizam água e energia elétrica e $83,82 \%$ relataram que conversam com outras pessoas sobre práticas ecológicas. Porém, ao se analisar outras ações sustentáveis, verificou-se que $37,87 \%$ dos envolvidos na pesquisa não utilizam papel reciclável e $68,01 \%$ não participam de eventos ou atividades ligadas ao meio ambiente.

Um dos principais desafios da sociedade moderna é reduzir o consumo de bens supérfluos ou de pouca necessidade, pois os resíduos deixados por estes bens são uma das principais formas de poluição do meio ambiente. Os participantes da pesquisa foram questionados sobre este tema, $50,74 \%$ afirmam que às vezes procuram reduzir o consumo de bens supérfluos, $27,21 \%$ responderam que reduziram o consumo de bens supérfluos pelos mais variados motivos e apenas $21,32 \%$ relataram que não desenvolvem ações que busquem uma redução no consumo dos bens supérfluos.

Muitas empresas buscam desenvolver ações que promovam a melhoria do meio ambiente pelos mais variados motivos, neste contexto os participantes da pesquisa foram questionados, onde 54,41\% afirmavam que às vezes compram produtos ecológicos ou compram produtos de empresas que estão engajadas com a causa ambiental, no entanto $35,66 \%$ não sabe se os produtos adquiridos são ecológicos ou de empresas que contribuem com a melhoria do meio ambiente.

Constatou-se que a grande maioria dos participantes da pesquisa não possui como prática o plantio de árvores, conforme informado por $69,12 \%$ dos entrevistados (Figura 2). Por meio da Figura 2 pode-se realizar uma análise dos principais problemas relacionados ao meio ambiente no dia a dia dos entrevistados, sendo possível com a implementação da educação ambiental, repensar e mudar algumas das atitudes dos participantes, para a criação de nova mentalidade onde se compreenda a importância que ações sustentáveis têm para a preservação e melhoria do meio ambiente.

Matos (2007) destaca que é necessária uma educação acerca das questões ambientais como toda educação, desenvolvendo diariamente a consciência crítica para levar a uma reflexão sobre o nosso processo civilizatório, procurando assim estabelecer uma nova ética nas relações entre as diferentes sociedades e a natureza. Já Gadotti (2000) afirma que a educação ambiental procura ter como embasamento o pensamento crítico e inovador em qualquer tempo ou lugar, em seu modo formal e não formal, promovendo a transformação e construção da sociedade, com objetivo de ajudar a desenvolver uma consciência ética sobre todas as formas de vida com as quais compartilhamos este planeta, respeitar seus ciclos vitais e impor limites a exploração dessas formas de vida pelos seres humanos. Neste contexto, pode-se compreender porque a grande maioria dos participantes desta pesquisa não desenvolvem ações sustentáveis, já que 68,01\% nunca participou de atividades ou palestras ligadas a causa ambiental, sendo muito importante desenvolver o tema ambiental com estes.

\section{Soluções para os problemas ambientais}

As principais causas dos problemas ambientais são conhecidas pela maior parte da população, no entanto, a solução para estes problemas é o grande desafio a ser alcançado pela sociedade. Neste contexto, questionaramse os participantes da pesquisa sobre quais seriam as ações a serem desenvolvidas para solução dos problemas ambientais. Como respostas $65,07 \%$ dos participantes afirmaram que a solução dos problemas ambientais depende das pequenas ações de todos, ou seja, das ações do dia a dia; $33,46 \%$ afirmaram que as soluções dependem dos governos e das grandes empresas; $0,37 \%$ responderam que não sabiam; $1,10 \%$ afirmaram que depende da mídia, incentivos à ciência e estudos e 1 participante não respondeu à pergunta. Neste contexto, Zimmermann (2016), ressalta que as soluções para a minimização dos impactos gerados pela degradação do meio ambiente devem iniciar pelo trabalho diário através do exercício da cidadania, realizando-se ações que minimizem os impactos gerados por cada indivíduo.

Já Reigota (2001) defende a política dos cinco R's a qual classifica como uma das principais estratégias a ser adotada na Educação Ambiental, e consequentemente, no enfretamento dos problemas ambientais, pois ela prioriza a redução do consumo e o reaproveitamento dos materiais, fomentando assim, a reciclagem dos materiais. Segundo o autor, os cinco R's fazem parte de um processo educativo que tem por objetivo uma mudança de hábitos no cotidiano dos cidadãos, trazendo bons resultados para quem as coloca em prática, beneficiando assim o meio ambiente.

\section{Agrotóxicos e qualidade de vida}

Atualmente, a grande maioria dos agricultores que possuem lavouras comerciais utilizam agrotóxicos para controle de pragas, doenças ou plantas daninhas. Como a maior parte dos participantes desta pesquisa são agricultores, questionou-se os mesmos sobre o uso de agrotóxicos em suas lavouras, $87,25 \%$ dos agricultores participantes da 
pesquisa afirmaram que fazem uso regular de agrotóxicos na sua lavoura para obter a produção agrícola desejada e apenas $12,75 \%$ relataram não utilizar agrotóxicos em sua produção agrícola. Assim, observa-se que a maioria dos agricultores utilizam agrotóxicos na produção de alimentos. Vários são os problemas causados ao meio ambiente pela utilização inadequada destes produtos químicos e Bohner et al. (2011) destacam que a utilização destes produtos não só é responsável pela contaminação ambiental, mas também é a causa de muitos problemas de saúde pública, pois quando aplicados inadequadamente prejudicam o meio ambiente, saúde dos trabalhadores rurais e dos consumidores.

Segundo Terrazzan \& Valarini (2009) para melhorar a qualidade de vida, muitas pessoas estão buscando alimentos orgânicos, é por isso que este mercado está em ritmo acelerado de crescimento em todo mundo. Neste contexto, os participantes da pesquisa foram questionados sobre a origem das verduras que consomem. Os resultados mostraram que $43,01 \%$ dos participantes desconhecem a origem das verduras que consomem, pois realizam suas refeições em restaurantes ou simplesmente não há informações suficientes nos locais onde as compram; $28,68 \%$ relataram que às vezes consomem verduras orgânicas, quando há disponibilidade para a compra; $25,37 \%$ responderam que consomem apenas verduras orgânicas, pois possuem plantio próprio, ou seja, realizam plantio de subsistência; $2,94 \%$ dos participantes não responderam a questão. Além de contribuir com melhor qualidade das pessoas, a alimentação a base de produtos orgânicos também contribui para a preservação do meio ambiente. Segundo Terrazzan \& Valarini (2009), os alimentos orgânicos são provenientes de um sistema de produção agrícola que visa manejar o solo, a água, os vegetais, animais, macro e microrganismos, buscando minimizar os impactos ambientais dessa atividade. Isso, segundo os mesmos autores citados, ocorre graças à eliminação do uso de agrotóxicos e de quaisquer adubos minerais de alta solubilidade nas práticas agrícolas, conservando-os em longo prazo e mantendo a harmonia desses elementos entre si e com os seres humanos. Como os produtos orgânicos geralmente apresentam um preço mais elevado, muitos consumidores não adquirem os mesmos. Neste contexto, os participantes da pesquisa foram questionados sobre esse aspecto e $72,43 \%$ afirmaram que pagariam mais caro por produtos (verduras) orgânicos e apenas $27,57 \%$ relataram que não pagariam a mais por produtos orgânicos.

A partir da realização da pesquisa e dos resultados encontrados, viu-se claramente a necessidade de implementar ações que poderiam contribuir para a mitigação dos impactos causados no meio ambiente, pois observou-se que existe uma carência de ações de Educação Ambiental. Fundamentado na pesquisa realizada e nas informações apresentadas, ações iniciais de Educação Ambiental foram realizadas com intuito de proporcionar aos envolvidos com uma Cooperativa de Crédito uma participação, conhecimento e disseminação de ações em prol do meio ambiente.

Atividades práticas e teóricas relacionadas à Educação Ambiental

Ao se analisar os dados obtidos por meio da aplicação dos questionários, verificou-se que os participantes deste estudo apresentavam poucos conhecimentos sobre os assuntos relacionados ao meio ambiente. Além disso, constou-se que alguns participantes consideram irrelevante trabalhar com temas relacionados ao meio ambiente. Diante deste contexto, percebeu-se a necessidade do desenvolvimento de atividades práticas e teóricas relacionadas à educação ambiental, a fim de contribuir para a melhoria dos conhecimentos práticos e teóricos dos participantes sobre a questão ambiental. Assim, realizaram-se diferentes atividades por meio das quais buscou-se desenvolver a consciência ambiental dos participantes, a fim de que mesmos contribuam para a criação de uma nova realidade local capaz de promover o desenvolvimento sustentável. Várias foram as atividades de educação ambiental realizadas, sendo que as mesmas foram apoiadas e desenvolvidas com base na proposta da Agenda 21 Brasileira, a qual priorizou a política dos cinco R's como uns de seus princípios (MMA, 2009).

No primeiro momento as atividades foram realizadas nas reuniões que aconteciam na Cooperativa com associados que participavam das "reuniões da habitação". As atividades desenvolvidas tinham como finalidade desenvolver a consciência cooperativa e ambiental, demonstrando aos participantes que por meio de pequenas mudanças nas ações do cotidiano é possível se alcançar soluções para os problemas ambientais. Estas atividades contaram com participação de 61 pessoas. Com estes participantes foram desenvolvidas seis atividades que incluíram palestras sobre a destinação dos resíduos domésticos e sobre adubação química, palestras sobre adubação orgânica e sua utilização em hortas, e atividades práticas, como: plantio de mudas de árvores nativas, fabricação de adubo orgânico para ser utilizado em hortas e a fabricação de sabão e sabonete a partir da reutilização de óleo de cozinha.

Com as ações de Educação Ambiental realizadas com este grupo de pessoas buscou-se contribuir para o processo de transformação da sociedade atual em uma sociedade sustentável, onde a conscientização vem 
ao encontro do exercício da cidadania, que considera a natureza como um bem comum, levando em conta a capacidade de regeneração dos recursos materiais, promovendo a distribuição equitativa da riqueza gerada e condições dignas de vida para as gerações atuais e futuras (Sader, 1992).
Com os demais associados da cooperativa, foram realizadas outras oito ações, que podem ser observadas na Tabela 2. No total foram alcançadas 288 pessoas; entre estas, 22 pessoas participaram de mais de uma ação; foram distribuídas 49 mudas de árvores nativas e plantadas outras 67.

Tabela 2 - Ações de Educação Ambiental desenvolvidas com os associados e colaboradores da Cooperativa

\begin{tabular}{|c|c|c|}
\hline Ação & Objetivo & $\begin{array}{l}\mathrm{N}^{\mathrm{o}} \text { de } \\
\text { participantes }\end{array}$ \\
\hline $\begin{array}{l}\text { Palestra sobre: } \\
\text { Reflorestamento. } \\
\text { (Distribuição de mudas de } \\
\text { árvores nativas) }\end{array}$ & $\begin{array}{l}\text { Promover a conscientização ambiental por meio de estudos sobre arborização } \\
\text { e reflorestamento - } 49 \text { mudas de árvores foram distribuídas e } 67 \text { mudas de } \\
\text { árvores foram plantadas na região de abrangência do estudo. }\end{array}$ & 58 \\
\hline $\begin{array}{l}\text { Palestra: Uso Consciente } \\
\text { da Cooperativa e na } \\
\text { Cooperativa }\end{array}$ & $\begin{array}{l}\text { Propor aos envolvidos conhecer o meio ambiente e ter ferramentas de } \\
\text { defesas usando os conhecimentos adquiridos; motivando a sensibilização } \\
\text { dos indivíduos; transformando diretamente o modo de agir e pensar; } \\
\text { formando opiniões sólidas e abrindo caminhos para a participação de todos. }\end{array}$ & 19 \\
\hline $\begin{array}{l}\text { Palestra: Plantio direto um } \\
\text { aliado do meio ambiente }\end{array}$ & $\begin{array}{l}\text { Qualificar os agricultores sobre a técnica mostrando os principais benefícios } \\
\text { que a mesma oferece a eles e ao meio ambiente }\end{array}$ & 42 \\
\hline $\begin{array}{l}\text { Palestra: Os principais } \\
\text { impactos causados ao } \\
\text { solo pelo cultivo de } \\
\text { monoculturas }\end{array}$ & $\begin{array}{l}\text { Conscientizar a população dos impactos negativos que plantio sequencial de } \\
\text { monoculturas traz ao solo e consequentemente ao meio ambiente }\end{array}$ & 36 \\
\hline $\begin{array}{l}\text { Palestra: Uso Consciente } \\
\text { dos Agrotóxicos e da } \\
\text { Adubação Química }\end{array}$ & $\begin{array}{l}\text { Informar os participantes sobre os riscos que utilização indiscriminada ou } \\
\text { inadequada dos agrotóxicos pode trazer saúde dos seres humanos e ao meio } \\
\text { ambiente. } \\
\text { Conscientizar a população da importância da utilização dos equipamentos } \\
\text { de proteção, e da dose recomenda. }\end{array}$ & 34 \\
\hline $\begin{array}{l}\text { Workshop: Produção de } \\
\text { Resíduos e Consumo } \\
\text { Sustentável }\end{array}$ & $\begin{array}{l}\text { Desenvolver a compreensão sobre a importância do consumo sustentável. } \\
\text { Concretizar sobre impactos causados ao meio ambiente sobre o descarte } \\
\text { inadequado de resíduos. }\end{array}$ & 30 \\
\hline $\begin{array}{l}\text { Palestra: Consumo de } \\
\text { Produtos Orgânicos e } \\
\text { Organização de Hortas } \\
\text { Orgânicas Domiciliares }\end{array}$ & $\begin{array}{l}\text { Orientar sobre importância de alimentação adequada, e dos benefícios de } \\
\text { consumir produtos orgânicos. } \\
\text { Despertar nos participantes o interesse de cultivar algumas verduras e } \\
\text { legumes que eles consomem diariamente, através da implantação de hortas } \\
\text { orgânicas em seus domicílios. }\end{array}$ & 51 \\
\hline
\end{tabular}

Workshop: Reciclagem e Reaproveitamento de Materiais

Demonstrar a importância que separação adequada dos matérias traz para reciclagem.

Capacitar os participantes sobre técnicas que podem ser utilizadas para o reaproveitamento e reciclagem de matérias.

\begin{tabular}{lc}
\hline Total de pessoas diferentes alcançadas & 266 \\
\hline Pessoas que participaram de mais de um evento & 22 \\
\hline Total de pessoas dos encontros da "Habitação" & 61 \\
\hline Total & 327 \\
\hline
\end{tabular}


A Educação Ambiental realizada com os associados da cooperativa, procurou colaborar para a promoção de uma sociedade mais sustentável. Desde a Primeira Conferência Intergovenamental sobre Educação Ambiental, realizada em 1977 em Tbilisi, Georgia, a Educação Ambiental é considerada um processo permanente e constante, no qual os sujeitos e a comunidade tomam consciência do meio ambiente e adquirem conhecimentos, valores, habilidades, atitudes, experiências e a determinação que os tornam aptos a agir individual e coletivamente para resolver problemas ambientais presentes e futuros (Dias, 1992).

Assim, a Educação Ambiental precisa ser implementada no cotidiano das pessoas, independentemente de fatores sócio demográficos, e ainda, precisa ser ação, precisa ser atitude na vida das pessoas, nas suas diversas possibilidades, abrindo um estimulante espaço para repensar práticas sociais, para que o desenvolvimento sustentável possa acontecer de maneira efetiva, com a realização de mais ações práticas.

\section{CONCLUSÕES}

A Educação Ambiental é ferramenta fundamental para a criação de novas atitudes na sociedade, principalmente relacionado ao meio ambiente, no entanto, são raras senão inexistentes as atividades que trabalham a educação ambiental com público adulto. Portanto, as atividades de educação ambiental desenvolvidas dentro da Cooperativa de Crédito contribuem para melhoria do convívio cooperativo, pois ampliaram os conhecimentos e estimularam as mudanças de valores, promovendo o aperfeiçoamento social e profissional na relação homem e meio ambiente, desenvolvendo um novo saber crítico e inovador em relação às novas práticas a serem seguidas, que promovem o desenvolvimento financeiro dos participantes e também preservam o meio ambiente.

Por fim, almeja-se que a Cooperativa de Crédito participante da pesquisa incorpore os conhecimentos compartilhados, tornando-se assim, uma importante difusora da Educação Ambiental e da sustentabilidade, contribuindo para uma sociedade mais justa, baseada na sustentação harmônica de seus pilares sociais, econômicos e ambientais.

\section{LITERATURA CITADA}

ALMEIDA, S.G.; CORDEIRO, A.; PETERSEN, P. Crise socioambiental e conversão ecológica da agricultura brasileira. Rio de Janeiro: ASPTA, 2001. 121p.
BOHNER, T.O. L.; ARAÚJO, L. E. B.; NISHIJIMA, T. O impacto ambiental do uso de agrotóxicos no meio ambiente e na saúde dos trabalhadores rurais. Revista Eletrônica do Curso de Direito da UFSM, v. 8, n.0, p. 329-341, 2013.

BRASIL. Lei $\mathrm{n}^{\circ}$. 12.305. Política nacional de resíduos sólidos. Brasília: Diário Oficial da União, 2 de agosto de 2010.

BRASIL. Lei $n^{\circ}$. 9. 795. Política nacional de educação ambiental. Brasília: Diário Oficial da União, 28 de abril de 1999.

BRASIL. Lei. $\mathrm{n}^{\circ}$. 5.764. Lei geral do cooperativismo. Brasília: Diário Oficial da União, 16 de dezembro de 1971.

CRESOL - COOPERATIVA DE CRÉDITO RURAL COM INTERAÇÃO SOLIDÁRIA. Conheça a Cresol. Francisco Beltrão: Site CRESOL, 2017. Disponível em: <http://www. cresol.com.br/site/conteudo_historia.php?id=1>. Acesso: 08 abr. 2017.

DIAS, G.F. Educação ambiental: princípios e práticas. São Paulo: Gaia, 1992. 400p.

FRANCISCO, W.C. Energia hidrelétrica. São Paulo: Mundo Educação, 2009. Disponível em <http://www. mundoeducacao.com.br/geografia/energia-hidreletrica. htm> Acesso em: 15 abr. 2017.

GADOTTI, M. Pedagogia da terra. São Paulo: Peirópolis, 2000. 217p.

GLIESSMAN, S. R. Agroecologia: processos ecológicos em agricultura sustentável. Porto Alegre: UFRGS, 2001. $653 \mathrm{p}$.

KUHNEN, A. Reciclando o cotidiano: representações sociais do lixo. Florianópolis: Letras Contemporâneas, 1995. 130p.

LEROY, J.P.; SCHLESINGER, S.; PÁDUA, J. A.; ACSELRAD, H. Tudo ao mesmo tempo agora: desenvolvimento, sustentabilidade, democracia: o que isso tem a ver com você? Petrópolis: Vozes, 2002. 198p.

MATOS, L. R. R. Políticas públicas e pedagógicas cotidianas: um estudo de caso dos PCN - Meio ambiente em Sorocaba. 84p. Dissertação (Mestrado em Educação) Universidade de Sorocaba, Sorocaba-SP, 2007.

MEDEIROS, M. C. S.; RIBEIRO, M. C. M. Meio ambiente e educação ambiental nas escolas públicas. Rio Grande: Âmbito Jurídico.com.br. 2018. Disponível em: $<$ www. ambitojuridico.com.br/site/index.php?n link=revista artigos leitura\&artigo $\mathrm{id}=10267 \&$ revista caderno $=5>$. Acesso em: $18 \mathrm{dez} .201 \overline{8}$. 
MMA - MINISTÉRIO DO MEIO AMBIENTE. A3P: Agenda ambiental na administração pública - Agenda 21 brasileira. Brasília: Secretaria de Articulação Institucional e Cidadania Ambiental/Departamento de Cidadania e Responsabilidade Socioambiental, 2009. 98p. Disponível em: < http://www.mma.gov.br/estruturas/a3p/_arquivos/ cartilha_a3p_36.pdf. >. Acesso em 05 dez. 2018.

MUGGLER, C. C.; SOBRINHO, P.A.F.; MACHADO, V. A. Educação em solos: Princípios, teoria e métodos. Revista Brasileira de Ciência do Solo, v. 30, n. 4, p. 733-740, 2006.

NAMORADO, R. Da cooperação ao direito cooperativo - para uma expressão jurídica da cooperatividade. Tese (Doutorado) - Faculdade de Economia da Universidade de Coimbra, Coimbra - Portugal, 1993.

O'LEARy, P. R.; WALSH, P. W. (1999). Decision maker's guide to solid waste management. Washington: U.S. Environmental Protection Agency, 199. 372p.

OCB SESCOOP-Organização das Cooperativas Brasileiras. Cooperativismo. Brasília: OCB, 2014. Disponível em: $<$ http://www.ocb.org.br/site/cooperativismo/index.asp $>$. Acesso em: 15 ago. 2017.

ORGANIZAÇÃO DAS COOPERATIVAS BRASILEIRAS- OCB. Orientação para constituição de cooperativas. Brasília: OCB, 1998.

PINHO, D. B. A doutrina cooperativa nos regimes capitalista e socialista. São Paulo: Pioneira, 1966.161p.

PRIETO, É. C. Universidade sustentável: desafios e compromissos da educação e da gestão ambiental na Universidade Federal de Uberlândia. 173p. Tese (Doutorado em Geografia) - Universidade Federal de Uberlândia Uberlândia, 2012.

REIGOTA, M. Meio ambiente e representação social. São Paulo: Cortez, 2001. 87p.

SADER, E. A ecologia será política ou não será. In: GOLDENBERG, M. org. Ecologia, ciência e política: participação social, interesses em jogo e luta de ideias no movimento ecológico. Rio de Janeiro: Revan, 1992. p.13542.

SAIDUR, R. Energy consumption, energy savings, and emission analysis in Malaysian office buildings. Energy Policy, v. 37, n. 10, p. 4104-4113, 2009.

SANTOS, T. S.; BATISTA, M. C.; POZZA, S. A.; ROSSI, L. $\mathrm{S}$. Análise da eficiência energética, ambiental e econômica entre lâmpadas de LED e convencionais. Engenharia Sanitária Ambiental, v. 20, n. 4, p. 595-602, 2015.

TERRAZZAN, P.; VALARINI, P.J. Situação do mercado de produtos orgânicos e as formas de comercialização no Brasil. Informações econômicas, v. 39, n. 11, p. 27-40, 2009.

UNESCO - ORGANIZAÇÃO DAS NAÇÕES UNIDAS PARA A EDUCAÇÃO, A CIÊNCIA E A CULTURA. Declaração mundial sobre educação para todos: satisfação das necessidades básicas de aprendizagem. Jomtien: UNESCO, 1990. 8p. Disponível em. $\quad<$ https://nova-escola-producao.s3.amazonaws. com/u9cKhbzBqvUEv8WFFdUqrwsMz8YGMKE9 NyhJemct59JpXAkngQjP56DAxN8W/086291 por. pdf>Acesso em: 05 jan 2019.

WCED - COMISSÃO MUNDIAL SOBRE MEIO AMBIENTE E DESENVOLVIMENTO. Nosso futuro comum. Rio de Janeiro: Editora da Fundação Getúlio Vargas, 1991. 430p.

ZIMMERMANN, N. Os cinco maiores problemas ambientais do mundo e suas soluções: Poluição do ar, desmatamento, extinção de espécies, degradação do solo e superpopulação representam grandes ameaças ao planeta. São Paulo: Carta Capital - Sustentabilidade. São Paulo, 2016. Disponível em: < https://www.cartacapital.com.br/ sustentabilidade/os-cinco-maiores-problemas-ambientaisdo-mundo-e-suas-solucoes>. Acesso em: 18 out. 2017.

Recebido para publicação em 17/09/2019 e aprovado em 28/12/2019. 